\title{
Integrin Adhesion Molecules in the Human Endometrium

\author{
Correlation with the Normal and Abnormal Menstrual Cycle
}

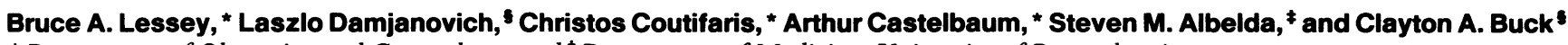

${ }^{*}$ Department of Obstetrics and Gynecology, and ${ }^{\ddagger}$ Department of Medicine, University of Pennsylvania,

and ${ }^{\S}$ Wistar Institute of Anatomy and Biology, Philadelphia, Pennsylvania 19104

\begin{abstract}
Integrins are a class of cell adhesion molecules that participate in cell-cell and cell-substratum interactions and are present on essentially all human cells. The distribution of nine different $\alpha$ and $\beta$ integrin subunits in human endometrial tissue at different stages of the menstrual cycle was determined using immunoperoxidase staining. Glandular epithelial cells expressed primarily $\alpha_{2}, \alpha_{3}$, and $\alpha_{6}$ (collagen/laminin receptors), while stromal cells expressed predominantly $\alpha_{5}$ (fibronectin receptor). The presence of $\alpha_{1}$ on glandular epithelial cells was cycle specific, found only during the secretory phase. Expression of both subunits of the vitronectin receptor, $\alpha_{v} \beta_{3}$, also underwent cycle specific changes on endometrial epithelial cells. Immunostaining for $\alpha_{v}$ increased throughout the menstrual cycle, while the $\beta_{3}$ subunit appeared abruptly on cycle day 20 on luminal as well as glandular epithelial cells. Discordant luteal phase biopsies ( $\geq 3$ d "out of phase") from infertility patients exhibited delayed epithelial $\beta_{3}$ immunostaining. These results demonstrate similarities, as well as specific differences, between endometrium and other epithelial tissues. Certain integrin moieties appear to be regulated within the cycling endometrium and disruption of integrin expression may be associated with decreased uterine receptivity and infertility. (J. Clin. Invest. 1992. 90:188-195.) Key words: collagen • laminin • fibronectin • vitronectin • infertility

\section{Introduction}

Over the past decade, investigators have come to recognize the importance of the extracellular matrix $(\mathrm{ECM})^{1}$ in directing the growth, differentiation and function of the overlying epithelium (1). The interaction between cell and substratum is mediated by several classes of cell adhesion molecules, one of the most important being the integrins (2-5). This diverse family of glycoprotein receptors is expressed on the cell membrane as heterodimeric $\alpha$ and $\beta$ subunits involved in both cell-cell and cell-substratum adhesion. Specific recognition and binding of extracellular matrix (ECM) components such as fibronectin (FN), laminin (LM), and collagen ( $\mathrm{Col}$ ) transmit information to the cytoskeletal structure (6), an interaction that may have

Address reprint request to Dr. Bruce 1. Lessey, University of Pennsylvania, 422 Curie Blvd., Philadelphia, PA 19104.

Received for publication 29 August 1991 and in revised form 17 January 1992.

1. Abbreviations used in this paper: Col, collagen; ECM, extracellular matrix; FN, fibronectin; LM, laminin; LPD, luteal phase dysfunction; OOP, out of phase.

J. Clin. Invest.

(c) The American Society for Clinical Investigation, Inc.

0021-9738/92/07/0188/08 \$2.00

Volume 90, July 1992, 188-195 major roles in promoting hormone responsiveness and genomic activation (1).

Although extensive information exists about specific integrin proteins (7), little is known concerning the distribution of these receptors in the female reproductive tract. Endometrium, composed of glandular epithelium and associated mesenchyme (stroma), maintains complex temporal and spatial functions in response to the cyclic hormonal milieu. The phenomena of cyclic endometrial replenishment, implantation, gestation, and parturition may require specific cell-cell and cell-substratum interactions.

As a first step in understanding the function of integrins in the human endometrium, we have examined their distribution throughout normal and abnormal menstrual cycles. Patients with inadequate corpus luteum function (luteal phase dysfunction; LPD) have delayed endometrial maturation and an associated infertility $(8,9)$. Since appropriately primed endometrium is thought to be necessary for normal cycle fecundity and uterine receptivity, we examined integrin distribution in endometrial biopsies from infertile women with significant endometrial dyssynchrony, and compared the results with the pattern observed in concordant samples. From these data it appears that some integrins normally undergo spatial and temporal changes in expression within the cycling endometrium, and that a disruption of this pattern may be associated with certain types of infertility in women.

\section{Methods}

Human samples. Endometrium was obtained from 35 reproductive age women at the time of hysterectomy at the Hospital of the University of Pennsylvania. Tissue was obtained from the early proliferative (day 5) through late secretory phase (day 28), and all hysterectomies were performed for benign disease. Endometrial biopsies were performed on women as part of their evaluation for infertility at the University of Pennsylvania. Use of endometrial tissue had been approved by the institutional review board of the University of Pennsylvania. All patients were cycling normally and none had received hormones for at least 3 mo before surgery. Dating of the endometrium was assessed according to the criteria of Noyes et al. (10). Endometrial biopsies were evaluated in the context of timing of ovulation and/or the onset of the next menstrual period. Samples were judged as "out of phase" if histologic dating was delayed by 3 or more days relative to the predicted day of the menstrual cycle. Proliferative endometrium was categorized based on histology and on last menstrual period. Samples were transported on ice to the laboratory where they were snap frozen on dry ice and stored at $-70^{\circ} \mathrm{C}$

Antibodies. Monoclonal antibodies (mAbs) P1H5, P1B5, P1D6 specific to $\alpha_{2}, \alpha_{3}$, and $\alpha_{5}$ subunits were generously provided by Drs. Elizabeth Wayner (University of Minnesota, Minneapolis, MN) and William Carter (Fred Hutchinson Cancer Research Center, University of Washington, Seatle, WA). Dr. Martin Hemler (Dana-Farber Cancer Institute, Boston, MA) kindly supplied mAbs TS2/7 and B-5H10 directed against the $\alpha_{1}$ and $\alpha_{4}$ subunits, respectively. GoH3, a specific mAb directed against $\alpha_{6}$ was donated by Dr. Arnoud Sonnenberg (Central Laboratory of The Netherlands Red Cross Transfusion Service, 
Amsterdam). Drs. Joel Bennett and James Hoxie (University of Pennsylvania) provided mAb SSA6 specific to the $\beta_{3}$ subunit, and $\mathrm{mAb}$ LM 142 against $\alpha_{\mathrm{v}}$ was provided by Dr. David Cheresh (Scripps Clinic, La Jolla, CA). The $\beta_{4}$ antibody was generously supplied by Dr. Steven Kennel (Oak Ridge National Laboratory, Oak Ridge, TN). These antibodies have previously been characterized (11-16).

Immunohistochemistry. Immunoperoxidase staining was performed on cryostat sections of endometrium throughout the menstrual cycle. Serial cryosections 4-8 $\mu$ thick were placed onto poly-L lysine coated slides, fixed in $-20^{\circ} \mathrm{C}$ acetone for $10 \mathrm{~min}$, and stained using Vectastain Elite ${ }^{\circledR B C}$ kits (Vector Laboratories, Burlingame, CA). Diaminobenzidine (DAB; Sigma Chem. Co., St. Louis, MO) was used as the chromagen. Primary antibody was placed on cryosections after blocking with $1 \%$ BSA in PBS, and allowed to bind at room temperature for $1 \mathrm{~h}$. A PBS pH 7.2-7.4 rinse was followed by secondary antibody consisting of biotinylated goat anti-mouse antibody for $30 \mathrm{~min}$. After a PBS rinse, the endogenous peroxidases were quenched with a 30-min incubation with $0.3 \% \mathrm{H}_{2} \mathrm{O}_{2}$ in absolute ethanol, followed by a 30-min rehydration in PBS. Avidin:biotinylated horseradish peroxidase macromolecular complex ( $\mathrm{ABC}$ ) was then incubated on the sections for $30 \mathrm{~min}$ before adding diaminobenzadine for $3 \mathrm{~min}$ to complete the reaction. Some samples were treated with 1:200 dilution of fluorescein-labeled anti-mouse antibodies for $1 \mathrm{~h}$ for immunofluorescent microscopy. Samples were subsequently washed in PBS and mounted. The resulting staining was evaluated on a Nikon microscope at low $(100 \times)$ and higher $(400 \times)$ magnification with or without fluorescence. Staining was judged as absent $(-)$, weak $( \pm)$, moderate $(+)$, or strong $(++)$. Examples of each are presented in Fig. 3 (see Results). Photomicrographs were made using Kodak T-MAX 100 ASA film.

Cell harvest and NP-40 extraction. Four samples of endometrium were obtained for further evaluation of the $\beta_{3}$ subunit in proliferative $(n=2)$ and late secretory $(n=2)$ endometrial epithelium. Each sample was placed in DMEM (Sigma Chemical Co.), supplemented with $10 \%$ fetal bovine serum (Flow Laboratories, Inc., McLean, VA) glucose (4,500 mg/liter), Hepes buffer ( $25 \mathrm{mM})$, L-glutamine ( $584 \mathrm{mg} /$ liter $)$, and sodium bicarbonate $(3.7 \mathrm{~g} /$ liter $)$. Using modifications of the procedures described by Gurpide and colleagues (17), endometrium was minced in a plastic petri dish before incubation with $6 \mathrm{mg}$ of collagenase (type 1A, $550 \mathrm{U} / \mathrm{mg}$; Sigma Chemical Co.) for $2 \mathrm{~h}$ at $37^{\circ} \mathrm{C}$. The resulting suspension was successively passed through a $250-\mu \mathrm{m}$ and a 38- $\mu \mathrm{m}$ seive (Newark Wire Cloth Co., Newark, $\mathrm{NJ}$ ). The coarse sieve removed undigested material, while the second retained the glandular elements and excluded the individual stromal and blood cells. After thorough rinsing, the glandular elements were obtained by backwashing with 10 to $20 \mathrm{ml}$ of DMEM. The isolated glandular structures were then transferred to a $1.5-\mathrm{ml}$ microfuge tube and centrifuged three times $(82 \mathrm{~g})$ for $2 \mathrm{~min}$ with intermittent washes with PBS. Membrane extracts were prepared by adding small volumes $(100-200 \mu \mathrm{l})$ of $10 \mathrm{mM}$ Tris-acetate, $\mathrm{pH} 8.0,0.5 \% \mathrm{NP}-40,0.5 \mathrm{mM} \mathrm{Ca}^{2+}$ (TNC) with $2 \mathrm{mM}$ PMSF to the final pellet, pipetted and incubated on ice for $15 \mathrm{~min}$. The lysate was centrifuged for $5 \mathrm{~min}$ at $16,000 \mathrm{~g}$ in a microcentrifuge. The resulting supernatant was called NP-40 extract and was frozen at $-70^{\circ} \mathrm{C}$ until use. A portion of the original, undigested tissue was cryosectioned for immunohistochemical localization of $\beta_{3}$.

Table I. Distribution of Integrins by Ligand Specificity

\begin{tabular}{ccc}
\hline & \multicolumn{2}{c}{ Ligand specificity } \\
\cline { 2 - 3 } & Collagen/laminin & Fibronectin/vitronectin \\
\hline \multirow{3}{*}{ Integrin subunit } & $\alpha_{1} / \beta_{1}$ & $\alpha_{4} / \beta_{1}$ \\
& $\alpha_{2} / \beta_{1}$ & $\alpha_{5} / \beta_{1}$ \\
& $\alpha_{3} / \beta_{1}$ & $\alpha_{v} / \beta_{1}$ \\
& $\alpha_{6} / \beta_{1}$ & $\alpha_{v} / \beta_{3}$ \\
& $\alpha_{6} / \beta_{4}$ & \\
& &
\end{tabular}

Gel electrophoresis and immunoblots. The protein concentration of each NP-40 extract and an extract of platelets (positive control) was determined using the technique described by Lowry et al. (18). Samples with equal amounts of protein were added to electrophoresis sample buffer (62.5 mM Tris base, $2 \%$ SDS, $10 \%$ glycerol, pH 6.8). Samples were analyzed by SDS-PAGE using $6 \%$ polyacrylamide gels, using nonreducing conditions (19). The gel was transferred to nitrocellulose using a transfer apparatus (Bio-rad Laboratories, Richmond, CA) and blocked with 4\% BSA in PBS with $0.2 \% \mathrm{Na}$ azide for $1 \mathrm{~h}$. After addition of primary antibody (SSA6 supernatant) for $2 \mathrm{~h}$, the gels were developed using an alkaline phosphatase-conjugated secondary antibody (Promega Corp., Madison, WI) according to methods previously described (20).

\section{Results}

Integrin distribution in normal endometrium. The distribution of $\alpha_{2}, \alpha_{3}, \alpha_{6}$, and $\beta_{4}$ subunits of integrins that recognize primarily collagen ( $\mathrm{Col}$ ) and/or laminin (LM; Table I) is shown in Fig. $1, A-D$. These subunits were present on glandular epithelium (arrows) throughout the menstrual cycle. Their distribution within the endometrium was typical of that seen for most epithelial tissues. The $\alpha_{2}$ and $\alpha_{3}$ subunits were distributed around the entire circumference of the cells, while the $\alpha_{6}$ and $\beta_{4}$ subunits appeared to be localized at the basolateral surface, adjacent to the basement membrane (BM) of the endometrial glands. The expression of these subunits by the mesenchyme (asterisks) was less pronounced. While moderate staining was seen for $\alpha_{6}$ on stromal cells (Fig. $1 C$ ), very little staining was noted for $\beta_{4}$.

The expression of the $\alpha_{4}$ and $\alpha_{5}$ subunits of integrins known to bind fibronectin (Table I) was quite restricted. The $\alpha_{4}$ subunit was undetectable above background staining (compare Fig. $1 E$ with Fig. $2 C$ ) in either epithelium or mesenchyme. The $\alpha_{5}$ subunit (Fig. $1 F$ ), representative of the classic fibronectin receptor, was not seen on the epithelial components, but was strongly expressed in the mesenchyme which is rich in fibronectin.

The intensity of immunostaining for three other subunits of integrins was found to change in a cycle-dependent manner. Immunostaining for $\alpha_{1}$ in the proliferative phase (Fig. $2 A$ ) was only slightly above background levels (Fig. $2 C$ ). The intensity of staining increased throughout the secretory phase (Fig. $2 B$ ). This intense circumferential staining was found on glandular and luminal epithelium on all samples from day 15 to 28 . Likewise, $\alpha_{\mathrm{v}}$ was weakly expressed on both the epithelium and mesenchyme in the proliferative phase (Fig. $3 A$ ) and staining increased gradually during the secretory phase to the level noted in Fig. $3 B$. During the proliferative phase $\beta_{3}$ staining was only present on the mesenchymal cells (Fig. $3 C$ ). Increased $\beta_{3}$ staining was apparent on the endometrial epithelium only after day 19 of the menstrual cycle (Fig. $3 D$ ) on the luminal as well as glandular epithelium, and was also present in a pericellular distribution. In contrast, the basalis layer did not significantly stain for either $\alpha_{\mathrm{v}}$ or $\beta_{3}$. This changing pattern of epithelial $\alpha_{\mathrm{v}}$ and $\beta_{3}$ throughout the cycle was studied in 35 endometrial samples and is depicted graphically in Fig. 4, $A$ and $B$.

Integrins in discordant endometrium. The presence of the epithelial $\beta_{3}$ subunit appeared to be a consistent internal marker of luteal phase maturation, and the timing of $\beta_{3}$ expression correlated with the putative periimplantation period. To investigate whether this phenomenon would be useful in the 

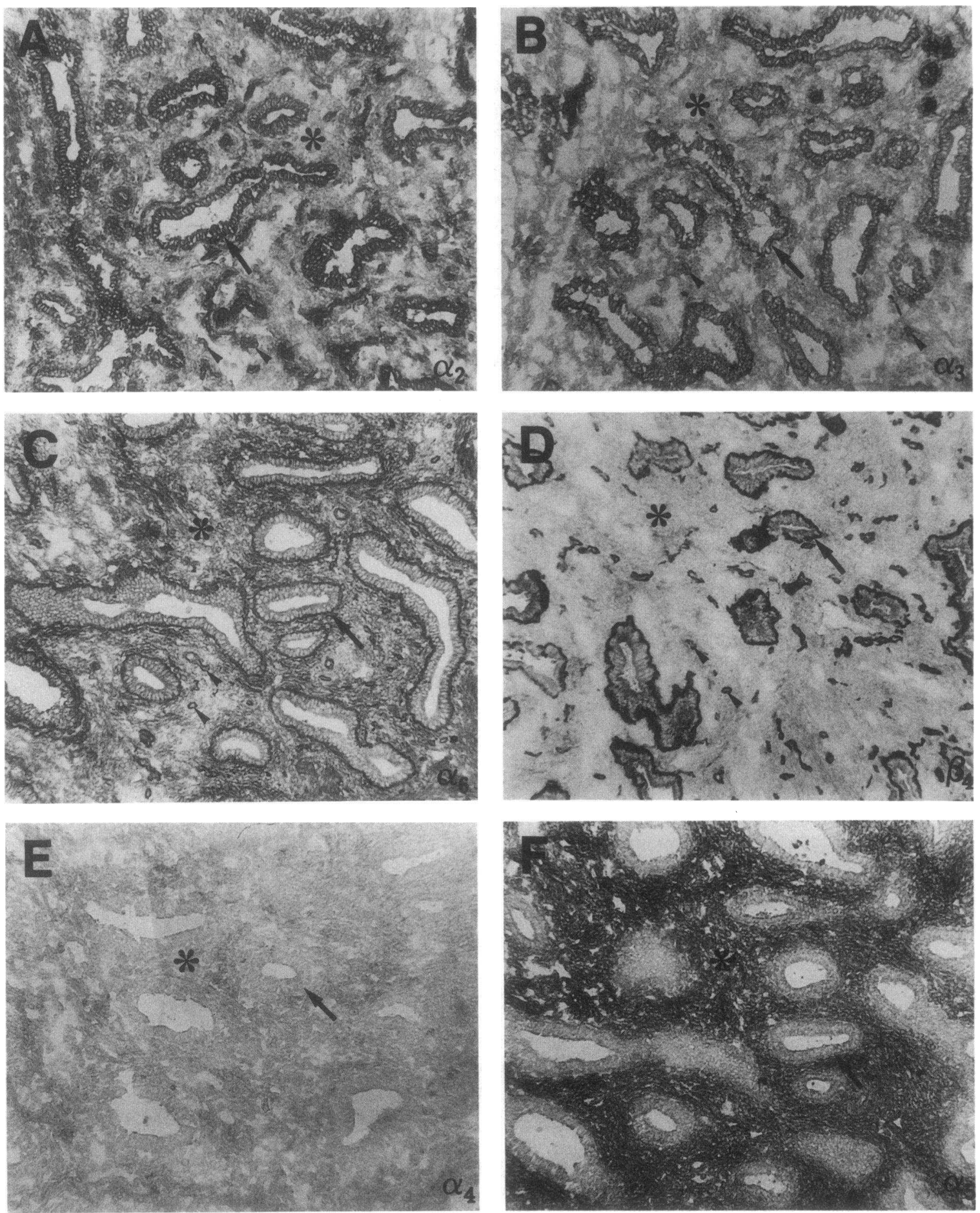

Figure 1. The immunohistochemical profile of six integrin subunits in normal endometrium. Immunohistochemical staining of the collagen/ laminin receptor subunits: $\alpha_{2}(A), \alpha_{3}(B), \alpha_{6}(C)$, and $\beta_{4}(D)$ shows prominent staining of epithelium (arrows) and microvessels (arrowheads) without significant stromal staining (asterisks) for $\alpha_{2}, \alpha_{3}$, and $\beta_{4}$. Note basolateral staining $\alpha_{6}$ and basal staining for $\beta_{4}$. Staining for fibronectin receptor subunits $\alpha_{4}(E), \alpha_{5}(F)$ show predominant mesenchyme staining (asterisks) with decreased epithelial staining (arrows). The immunoreactions ( areas of dark staining) were developed by the avidin-biotin-peroxidase complex using diaminobenzidine as a chromagen. For greater sensitivity, no counterstain was applied. $\times 125$.

clinical evaluation of endometrial biopsies, immunostaining was performed on luteal phase endometrial samples from cycles that showed evidence of maturational delay. Endometrial biopsies from 25 women who had concordance of menstrual and histologic dating ("normal" group) were compared to 12 biopsies that were identified as $\geq 3 \mathrm{~d}$ out of phase (OOP), based on either the time of ovulatory or the subsequent menses. Samples were immunostained for $\alpha_{1}, \alpha_{\mathrm{v}}$, and $\beta_{3}$ subunits. All biopsies were performed on days 20-24 of the menstrual cycle. In all instances, immunostaining for these three antigens was present on endometrial epithelia from the normal group. In biopsies that were delayed by $3 \mathrm{~d}$ or more, $\alpha_{1}$ and $\alpha_{\mathrm{v}}$ 

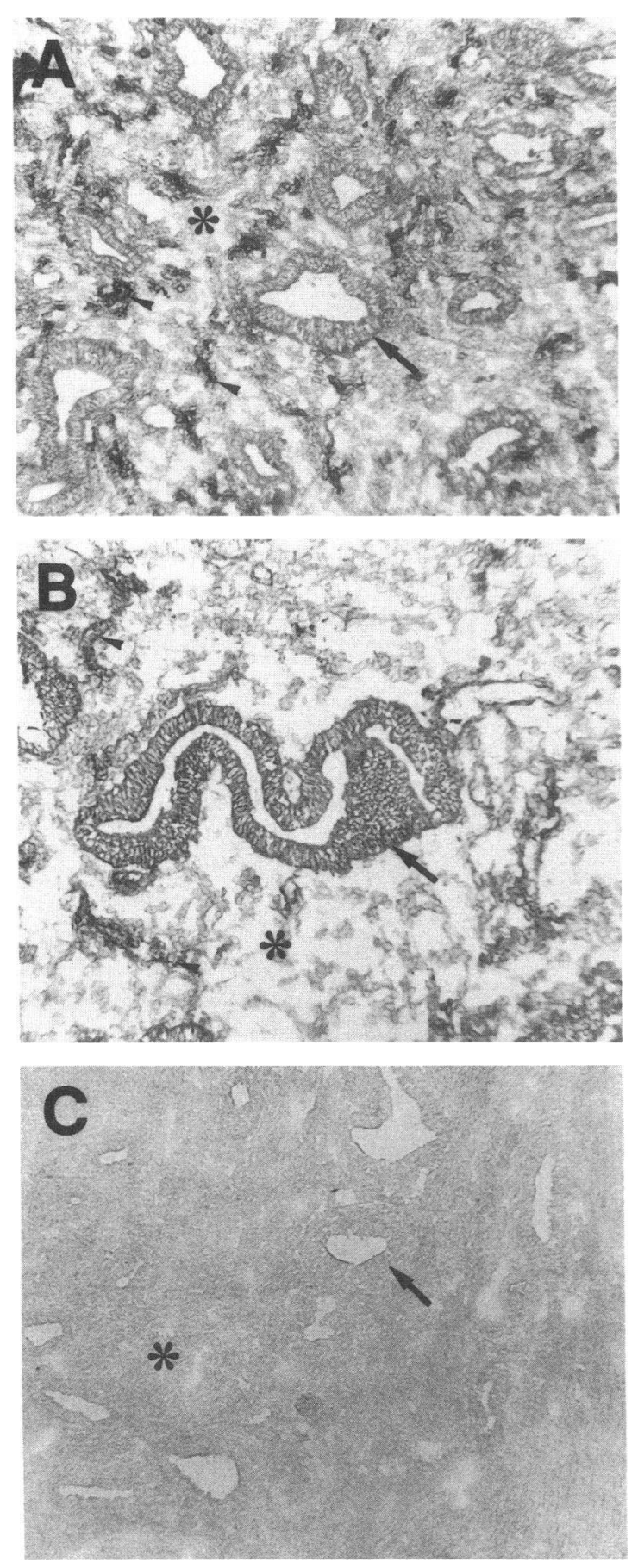

Figure 2. Photomicrographs of the immunohistochemical staining for the integrin subunit $\alpha_{1}$ in proliferative vs. secretory endometrium. The staining in the glandular epithelium (arrows) was largely absent in the proliferative phase $(A)$, but quite pronounced in all sections after menstrual cycle day 14 ( $B$; day 20 endometrium). The mesenchyme (asterisks) did not stain for $\alpha_{1}$. The microvasculature (arrowheads) staining was also pronounced, but did not change throughout the menstrual cycle. The staining noted in secretory endometrial glands was significantly higher than that of background $(C) . \times 125$.

staining was present, but epithelial $\beta_{3}$ staining was absent. The comparison of $\beta_{3}$ staining intensity in the two groups is shown in Fig. $5 \mathrm{~A}$. Accompanying photomicrographs of $\beta_{3}$ immunostaining from out of phase biopsies (OOP; B) and normal "in phase" biopsies $(C)$ are included, which demonstrates the discrepancy seen in $\beta_{3}$ staining. In subsequent treatment cycles, two OOP patients underwent repeat biopsy during a normalized cycle at which time immunostaining for epithelial $\beta_{3}$ was present. This suggests that the lack of $\beta_{3}$ was not an intrinsic defect in the OOP group. Rather, the discordant biopsies that lacked $\beta_{3}$ had not yet established the midluteal phenotype of normal day 20-24 endometrium.

To further demonstrate that immunohistochemical staining accurately reflected changes in the expression of $\beta_{3}$ subunit on endometrial epithelium, immunoblots (Western blots) were performed on samples of enriched endometrial glandular elements from proliferative and secretory phase. As shown in Fig. $6 \mathrm{~A}$, proliferative phase epithelial structures had little to no immunostaining at $95 \mathrm{~K}$ (lanes 2 and 3 ), compared with the positive control ( platelet extract; lane 1) or to samples from the secretory phase (lanes 4 and 5 ) which showed strong staining for $\beta_{3}$. The isolated endometrial glands appeared as tubular structures free of surrounding stroma (Fig. $6 B$ ). Immunofluorescent staining for $\beta_{3}$ from samples corresponding to lanes 3 and 4 (midproliferative phase and day 23 , respectively) are shown in Fig. 6, $C$ and $D$. Note the absence of glandular staining in the proliferative sample, while both glandular and luminal immunostaining is obvious from the secretory phase. These data confirm that the expression of epithelial $\beta_{3}$ in human endometrium is a cycle-specific phenomenon.

\section{Discussion}

The endometrium undergoes well-delineated changes in its histology throughout the menstrual cycle. We examined the expression of integrins within the context of these cyclic changes and found an interesting pattern of distribution for these cell adhesion molecules. A summary of the expression of integrin subunits throughout the menstrual cycle is shown in Table II. Collagen/laminin receptors (Table I) characterized by $\alpha_{2}, \alpha_{3}$, and $\alpha_{6}$ were uniformly expressed throughout the menstrual cycle, with a distribution similar to that seen for most other epithelia (21-25). The pericellular distribution of $\alpha_{2}$ and $\alpha_{3}$ subunits was distinctly different from that of $\alpha_{6}$ subunit. Characteristic of a LM receptor, $\alpha_{6}$ was concentrated on the basolateral surface. The $\beta_{4}$ subunit that pairs with $\alpha_{6}$ (16) was also found distributed on the basolateral surface of the epithelial cells, and its distribution appeared even more restricted to the basal pole. Given the presence of stromal $\alpha_{6}$ staining without $\beta_{4}$, it is likely that $\alpha_{6}$ pairs with $\beta_{1}$ in the mesenchyme. While the ligand for $\alpha_{6} \beta_{1}$ has been well characterized as the E8 fragment of laminin (26), the functioning of $\alpha_{6} \beta_{4}$ is less defined $(26,27)$. It appears likely, however, that $\alpha_{6} \beta_{4}$ also binds to laminin (28). The significance of this segregation of these laminin receptors between cell types is unknown. The $\alpha_{5} \beta_{1}$ integrin, a major fibronectin receptor, was also uniformly expressed throughout the menstrual cycle. Unlike the Col and LM receptors, the distribution of $\alpha_{5} \beta_{1}$ was limited to the mesenchyme.

For the most part, the distribution of these subunits corresponds to that which would be predicted from their function as both cell-cell and cell-matrix receptors (29), and from the reported distribution of ECM components. It has been postulated that these differences in distribution denote defined roles for these integrins (30-32). The integrins composed of $\alpha_{2}, \alpha_{3}$, 

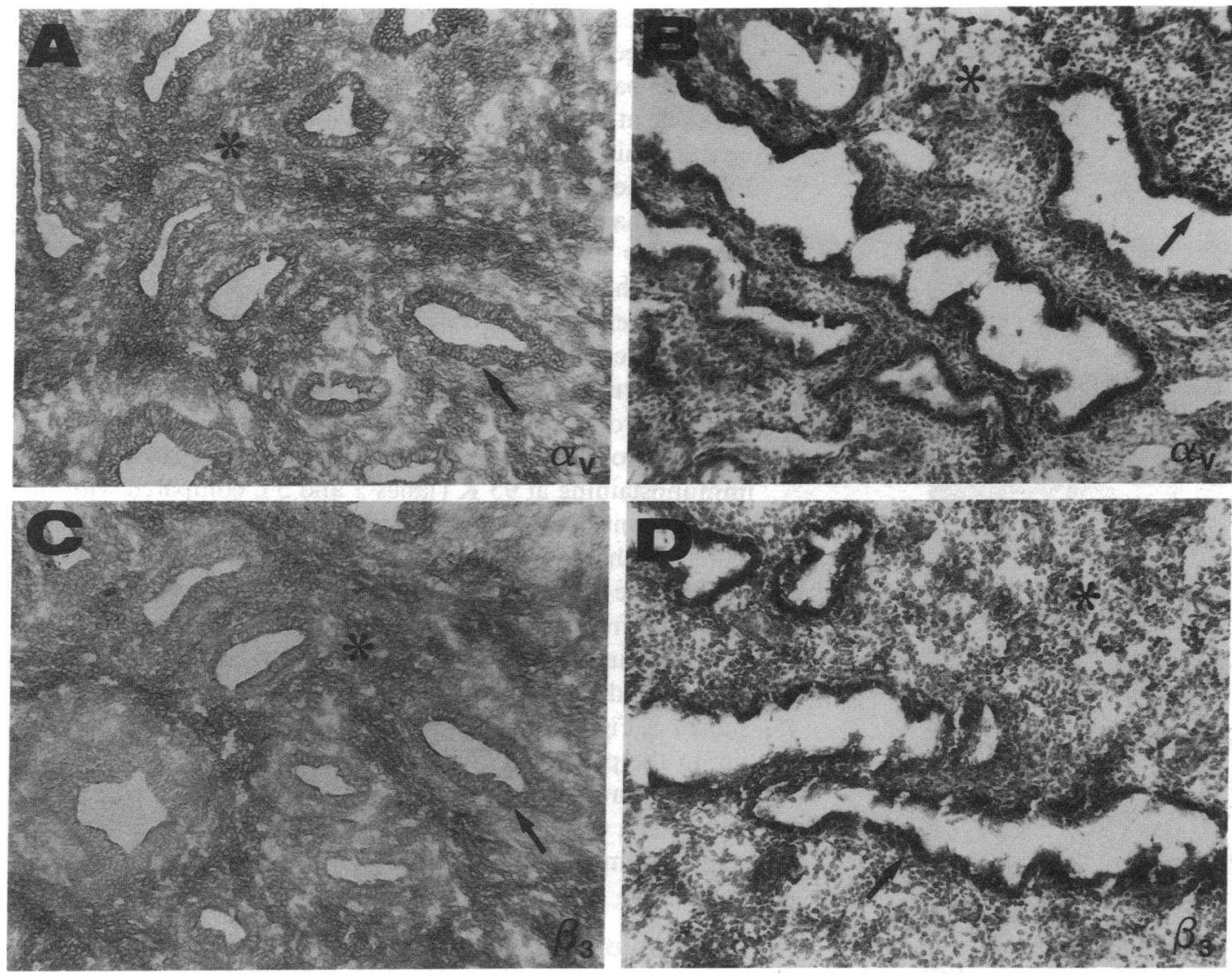

Figure 3. Immunostaining of $\alpha_{v}$ and $\beta_{3}$ in proliferative phase vs. secretory phase endometrium. The staining intensity of $\alpha_{\mathrm{v}}$ in the proliferative phase (A) was judged as "+" for the stromal cells (asterisks) and " \pm " for glandular $\alpha_{\mathrm{v}}$ (arrow). Immunostaining for $\alpha_{v}$ in day 22 endometrium $(B)$ demonstrates a significant increase in glandular staining (example of " ++ " staining intensity). Likewise, the staining for $\beta_{3}$ was absent in proliferative epithelium ( $C$; arrows) and was notably increased in this day 22 secretory endometrium (D). $\times 125$. and $\alpha_{6}$ are known to bind to Col and LM, components found in $\mathrm{BM}$, and thus, their expression largely on endometrial epithelial cells is not unexpected. Two of these subunits, $\alpha_{2}$ and $\alpha_{3}$, are known to promote epithelial cell-cell adhesion $(29,30)$, and this function is consistent with their pericellular rather than basal distribution. The intense staining for $\alpha_{5}$ in the mesenchyme is likewise paralleled by a rich distribution of fibronectin in this compartment of the endometrium (33).

In contrast to the receptors that were uniformly expressed at all stages of endometrial development, the distribution of several subunits for integrins was found to change with the advancement of the menstrual cycle. The $\alpha_{1}$ subunit, a Col/ LM binding receptor, was present on secretory but not proliferative endometrial epithelium. This subunit has previously been documented on secretory stage endometrium (34), and its expression in human endometrial explants was shown to be progestin dependent (35). The function of $\alpha_{1}$ in endometrial epithelium remains poorly understood, though the pericellular distribution may portend a role in cell-cell adhesion.

The $\alpha_{\mathrm{v}}$ integrin subunit is known for its ability to associate with a number of $\beta$ subunits, forming integrins capable of binding to fibronectin, fibrinogen, vitronectin, thrombospondin, and von Willebrand's factor (36-38). The temporal pattern of distribution for this subunit in endometrium was rather interesting. Immunostaining was first detected before the secretory phase with an increase in intensity throughout the cycle. While it is not possible to tell which $\beta$ molecule the $\alpha_{\mathrm{v}}$ subunit is paired with using immunohistochemistry, its ability to bind to $\beta_{1}, \beta_{3}, \beta_{5}$, or $\beta_{6}(36-41)$ suggests that $\alpha_{\mathrm{v}}$ may have multiple functions in human endometrium.
One subunit known to pair with $\alpha_{\mathrm{v}}$ is $\beta_{3}$, whose pattern of immunostaining on endometrial epithelial cells was quite unusual. Western blot analysis appears to confirm immunohistochemical staining that endometrial epithelial cells possess little if any $\beta_{3}$ until the midluteal phase. Epithelial $\alpha_{\mathrm{v}} \beta_{3}$ is remarkable for several reasons. First, $\beta_{3}$ is not characteristically pres-
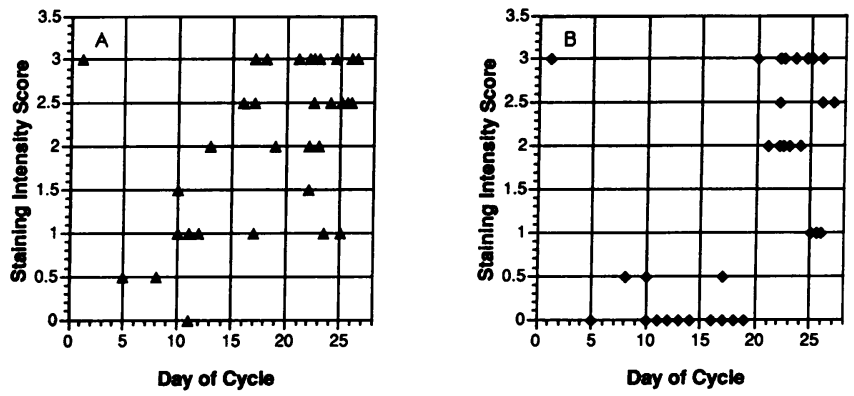

Figure 4. Relative intensity of staining for the epithelial $\alpha_{\mathrm{v}}$ and $\beta_{3}$ subunits in 35 endometrial samples throughout the menstrual cycle. The pattern of expression for $\alpha_{v}$ is shown in $A$, showing a gradual increase in staining throughout the menstrual cycle. Contrast this to the pattern for $\beta_{3}$ in $B$, showing a more abrupt rise in this integrin subunit around day 20 of the menstrual cycle. As described in the Methods section, samples were staged according to the last menstrual cycle, as well as by the histologic criteria of Noyes et al. (10). Sections were assigned a score of 0 ( - ; negative ), 1 ( \pm ; weak), 2 ( + ; moderate), or 3 ( ++ ; strong), by a blinded observer, and confirmed by a second observer. 

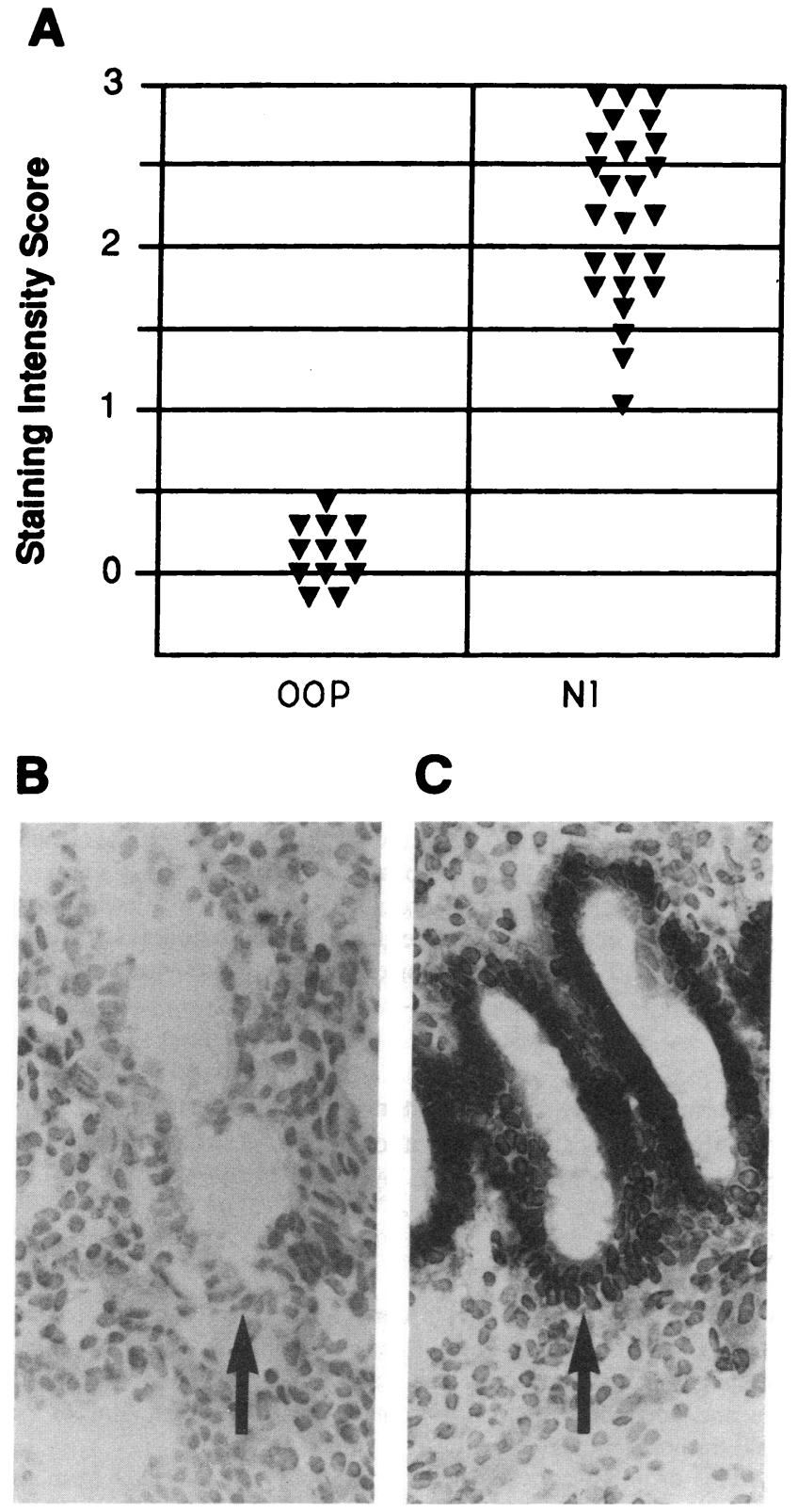

Figure 5. Staining intensity of epithelial $\beta_{3}$ in 12 infertility patients with delayed endometrial maturation. Endometrium was collected as described in the Methods section, from women undergoing evaluation for infertility. The biopsies were separated into two groups based on the correlation between histologic criteria and the menstrual cycle dating based on the time of ovulation and/or the subsequent menstrual period. Patients with endometrial biopsies 3 or more days out of phase (OOP group) were compared with 25 endometrial biopsies that were in phase ( Normal) and shown in $A$. Sections were assigned a score of $0(-$; negative $), 1$ ( \pm ; weak $), 2(+$; moderate $)$, or $3(++$; strong), based on the intensity of epithelial $\beta_{3}$ staining. Examples of immunohistochemical staining of an out of phase biopsy $(B)$ and a normal in phase sample $(C)$ is included to contrast the epithelial $\beta_{3}$ staining in each group. $\times 400$.

ent on epithelial cells. Second, the abrupt appearance of the $\beta_{3}$ subunit after day 19 suggests that expression of the vitronectin receptor is regulated in human endometrium. Third, the in- creased epithelial $\alpha_{\mathrm{v}} \beta_{3}$ staining in normal cycles correlates to a putative "implantation window" thought to exist within the secretory phase. In studies that examined the concept of an implantation window, Navot and co-workers (42) using donor oocytes in prepared recipients reported data on success of in vitro fertilization (IVF) cycles based on the time of embryo transfer. Though the numbers are small, when the data is expressed as pregnancy per transfer, the highest success rate was noted around day 19 of the menstrual cycle. It is important to point out that the physiologic basis for this window has not yet been established. These data suggest a possible role for integrins in the initial interaction between maternal and embryonic cells, and may participate in the establishment of an endometrial period of receptivity.

Available ligands present on the developing embryo are consistent with this hypothesis. Vitronectin is present on fetal membrane tissues (43), and evidence that vitronectin and fibronectin are involved in trophoblast attachment and outgrowth has previously been demonstrated in the mouse blastocyst (44). Trophoblast attachment in vitro can be blocked with RGD-containing peptides, providing additional evidence for integrin involvement in trophoblast adhesion (45). Recently, data have accumulated suggesting that trophoblasts elaborate an alternatively spliced form of fibronectin, oncofetal fibronectin (46). Feinberg et al. (47) have suggested that this form of FN is a specific marker for the extravillous trophoblast and may provide the matrix for trophoblast-endometrial interaction. Thus, epithelial $\alpha_{v} \beta_{3}$ could play a role in early fetal attachment, while mesenchymal $\alpha_{\mathrm{v}}(\beta$ ?) participates in maintaining a fetal/maternal interface in the ongoing pregnancy.

Involvement of $\alpha_{v} \beta_{3}$ in implantation is consistent with the observation that this integrin is lacking in midluteal biopsies from women whose endometrial progression is retarded. Immunostaining for $\beta_{3}$ in normal endometrium provides a useful internal landmark of luteal phase development, and its delayed expression in these patients may provide a new diagnostic modality for the evaluation of LPD. Traditionally, endometrial biopsies are performed on or after postovulatory day 10 (day 25 of the cycle). Since patients with LPD who undergo biopsy later than day 24 may eventually "catch up" and express this antigen, the earlier timing of endometrial biopsies as performed in this study will likely be a critical consideration in establishing the use of $\beta_{3}$ testing for this disorder. Once the specific cellular events relating to embryo attachment are better defined, the use of endometrial biopsy during the putative window of endometrial receptivity (day 20-24) may be more appropriate.

The process whereby integrins are regulated in the endometrium has yet to be established. While the timing of $\alpha_{1}$ expression appears to be progestin dependent, the situation for $\alpha_{\mathrm{v}}$ and $\beta_{3}$ appears to be more complex. A declining ratio of estradiol to progesterone may correlate better than progesterone alone, with the expression of one or both of these subunits. We and others have noted a decrease in epithelial (but not stromal) progesterone receptors that is maximal by day 20 of the menstrual cycle $(48,49)$, independent evidence that midluteal epithelial cells undergo dynamic changes in steroid responsiveness that may account for the onset of $\beta_{3}$ expression. Based on recent studies $(50,51)$, it would not be surprising to find that growth factors also play a role in the expression of certain endometrial integrins. 
A

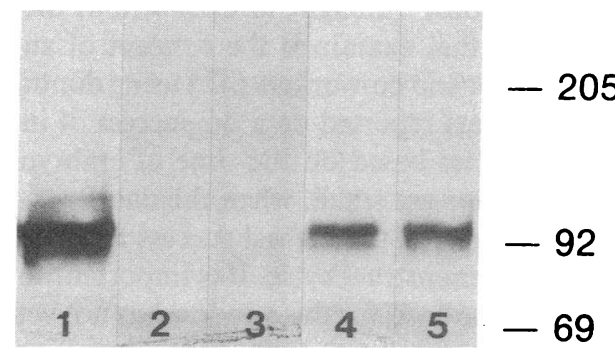

B

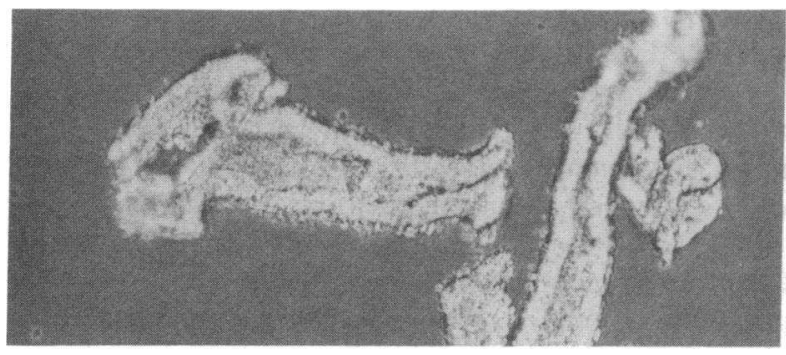

C

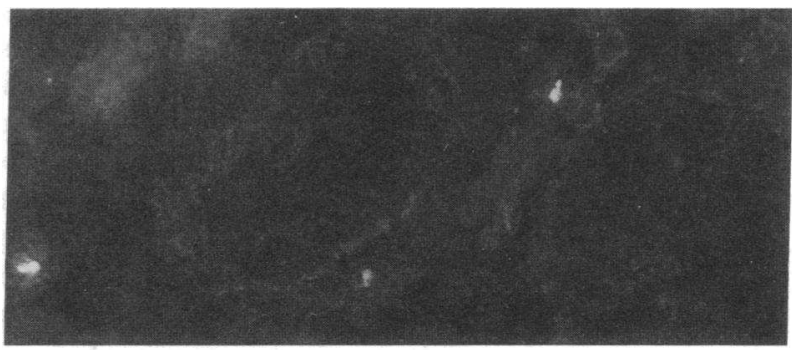

D

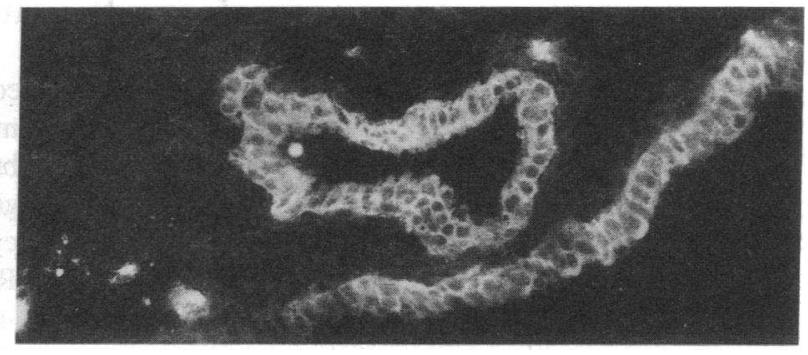

Figure 6. Immunoblot analysis of proliferative and secretory endometrium, stained for the $\beta_{3}$ subunit. $(A)$ Immunoblot of platelet extract (lane 1 ), compared with two samples from the early and mid-proliferative phase (lanes 2,3 ) and from the luteal phase (lane 4 and 5 ; days 23 and 26 , respectively) demonstrates a band at $\sim 95,000 \mathrm{~mol} \mathrm{wt}$, corresponding to $\beta_{3}$. Samples of endometrium were partially digested with collagenase and the glandular elements obtained $(B)$, using a modification of the methods of Satyaswaroop et al. (17). The glands appear as hollow structures free from surrounding stroma. Immunofluorescence of samples from lanes 3 and 4 ( $C$ and $D$, respectively) corresponds to the absence or presence of the $95-\mathrm{kD}$ band in $A$. $\times 400$.

In summary, integrin expression by the endometrium is an interesting and dynamic process. The endometrial epithelium expresses integrin subunits such as $\beta_{3}$ that have not been noted for most other epithelia. Integrin expression appears to be predictable, based on the time in the menstrual cycle, making the use of integrins of diagnostic use as stage-specific markers in

Table II. Distribution of Integrin Subunits in Normal Endometrium during the Menstrual Cycle

\begin{tabular}{|c|c|c|c|c|c|c|c|c|c|}
\hline & \multicolumn{5}{|c|}{ Col/LM } & \multicolumn{4}{|c|}{ FN/VN } \\
\hline & $\alpha 1$ & $\alpha 2$ & $\alpha 3$ & $\alpha 6$ & $\beta 4$ & $\alpha 4$ & $\alpha 5$ & $\alpha \mathbf{v}$ & $\beta 3$ \\
\hline \multicolumn{10}{|l|}{ Epithelial } \\
\hline $\begin{array}{l}\text { Proliferative } \\
\text { Early }\end{array}$ & 0 & ○ & $\bullet$ & $0^{*}$ & * & 0 & 0 & 0 & 0 \\
\hline secretory & 0 & $\bullet$ & 0 & - & ○ & 0 & 0 & 0 & O \\
\hline Late & & & & & & & & & \\
\hline secretory & $\bullet$ & $\bullet$ & - & ○ & 0 & 0 & 0 & - & 0 \\
\hline \multicolumn{10}{|l|}{ Stromal } \\
\hline $\begin{array}{l}\text { Proliferative } \\
\text { Early }\end{array}$ & $\mathrm{O}$ & 0 & 0 & 0 & $\mathrm{O}$ & $\bigcirc$ & 0 & 0 & ○ \\
\hline secretory & 0 & 0 & 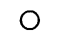 & 0 & $\mathrm{O}$ & 0 & 0 & 0 & ○ \\
\hline \multicolumn{10}{|l|}{ Late } \\
\hline secretory & 0 & 0 & 0 & 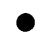 & $\mathrm{O}$ & 0 & 0 & 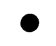 & ○ \\
\hline
\end{tabular}

- Corresponds to + or ++ staining.

- Corresponds to \pm staining.

O Corresponds to - staining.

* Signifies basolateral distribution of staining. this tissue. Finally, an understanding of the function of integrins throughout the menstrual cycle, and a means to regulate their expression may prove to be of future therapeutic use.

\section{Acknowledgments}

We would also like to express our appreciation to Drs. Elizabeth Wayner, William Carter, Steven Kennel, Martin Hemler, Arnoud Sonnenberg, Joel Bennett, James Hoxie, and David Cheresh for their generous and unconditional contributions of antibodies, and Aracelis Poleski for her technical assistance.

This project was supported in part by grant IN-135-J from the American Cancer Society and B.R.S.G. S07-RR-05415-29 awarded by the Biomedical Research Support Grant Program, Division of Research Resources, National Institutes of Health (B. A. Lessey); grants HL-01587 (S. M. Albelda), and HL 39023 (C. A. Buck) from the National Heart, Lung and Blood Institute; grants CA-19144 (C. A. Buck) and CA-10815 (C. A. Buck) from the National Cancer Institute; and grants from the Berlex Foundation, (B. A. Lessey), W. W. Smith Charitable Trust, The Mellon Foundation and the American Cancer Society (S. M. Albelda).

\section{References}

1. Getzenberg, R. H., K. J. Pienta, and D. S. Coffey. 1990. The tissue matrix: cell dynamics and hormone action. Endocr. Rev. 11:399-417.

2. Albelda, S. M., and C. A. Buck. 1990. Integrins and other cell adhesion molecules. FASEB (Fed. Am. Soc. Exp. Biol.) J. 4:2868-2880.

3. Ruoslahti, E., and M. D. Pierschbacher. 1987. New perspectives in cell adhesion: RGD and integrins. Science (Wash. DC). 238:491-497.

4. Hynes, R. O. 1987. Integrins: a family of cell surface receptors. Cell. 48:549-554.

5. Buck, C. A., and A. F. Horowitz. 1987. Integrin, a transmembrane glycoprotein complex mediating cell-substratum adhesion. J. Cell Sci. Suppl. 8:231250. 
6. Burridge, K., F. Karl, T. Kelly, G. Nuckolls, and C. Turner. 1988. Focal adhesions: transmembrane junctions between the extracellular matrix and the cytoskeleton. Annu. Rev. Cell Biol. 4:487-525.

7. Hemler, M. E. 1990. VLA proteins in the integrin family: structures, functions, and their role on leukocytes. Annu. Rev. Immunol. 8:365-400.

8. Soules, M. R., R. I. McLachlan, M. Ek, K. D. Dahl, N. L. Cohen, and W. J. Bremner. 1989. Luteal phase deficiency: characterization of reproductive hormones over the menstrual cycle. J. Clin. Endocrinol. Metab. 69:804-812.

9. McNeely, M. J., and M. R. Soules. 1988. The diagnosis of luteal phase deficiency: a critical review. Fertil. Steril. 50:1-15.

10. Noyes, R. W., A. T. Hertig, and J. Rock. 1950. Dating the endometrium. Fertil. Steril. 1:3-8.

11. Albelda, S. M., M. Daise, E. M. Levine, and C. A. Buck. 1989. Identification and characterization of cell-substratum adhesion receptors on cultured human adult large vessel endothelial cells. J. Clin. Invest. 83:1992-2002.

12. Carter, W. G., E. A. Wayner, T. S. Bouchard, and P. Kaur. 1990. The role of integrins $\alpha_{2} \beta_{1}$ and $\alpha_{3} \beta_{1}$ in cell-cell and cell-substrate adhesion of human epidermal cells. J. Cell Biol. 110:1387-1404.

13. Cheresh, D. A., and J. R. Harper. 1987. Arg-Gly-Asp recognition by a cell adhesion receptor requires its $130-\mathrm{kD} \alpha$-subunit. J. Biol. Chem. 262:1434-1437.

14. Hemler, M. E., C. Huang, Y. Takada, L. Schwarz, J. L. Strominger, and M. L. Clabby. 1987. Characterization of the cell surface heterodimer VLA-4 and related peptides. J. Biol. Chem. 262:11478-11485.

15. Sonnenberg, A., H. Janssen, F. Hogervorst, J. Calafat, and J. Hilgers. 1987. A complex of platelet glycoproteins Ic and IIa identified by a rat monoclonal antibody. J. Biol. Chem. 262:10376-10383.

16. Sonnenberg, A., C. J. Linders, J. H. Daams, and S. J. Kennel. 1990. The $\alpha_{6} \beta_{1}$ (VLA-6) and $\alpha_{6} \beta_{4}$ protein complexes: tissue distribution and biochemical properties. J. Cell Sci. 96:207-217.

17. Satyaswaroop, P. G., R. S. Bressler, M. M. De LaPena, and E. Gurpide. 1979. Isolation and culture of human endometrium glands. J. Clin. Endocr. Metab. 48:639-641.

18. Lowry, O. H., N. J. Rosebrough, A. L. Farr, and R. J. Randall. 1951. Protein measurement with Folin phenol reagent. J. Biol. Chem. 193:265-271.

19. Laemmli, U. K. 1970. Cleavage of structural proteins during assembly of the head of bacteriophage T4. Nature (Lond.). 227:680-685.

20. Albelda, S. M., P. D. Oliver, L. H. Romer, and C. A. Buck. 1990. EndoCAM: a novel endothelial cell-cell adhesion molecule. J. Cell Biol. 110:12271237.

21. Peltonen, J., H. Larjava, S. Jaakkola, H. Gralnick, S. K. Akiyama, S. S. Yamada, K. M. Yamada, and J. Uitto. 1989. Localization of integrin receptors for fibronectin, collagen, and laminin in human skin. Variable expression in basa and squamous cell carcinomas. J. Clin. Invest. 84:1916-1923.

22. Choy, M.-Y., P. I. Richman, M. A. Horton, and T. T. MacDonald. 1990 Expression of the VLA family of integrins in human intestine. J. Pathol. 160:3540.

23. Simon, E. E., and J. A. McDonald. 1990. Extracellular matrix receptors in the kidney cortex. Am. J. Physiol. 258:F783-F792.

24. Albelda, S. M. 1991. Endothelial and epithelial cell adhesion molecules. Am. J. Respir. Cell Mol. Biol. 4:195-203.

25. Hertle, M. D., J. C. Adams, and F. M. Watt. 1991. Integrin expression during human epidermal development in vivo and in vitro. Development (Camb.). 112:193-206.

26. Sonnenberg, A., P. W. Moddermann, and F. Hogervorst. 1988. Laminin receptor on platelets in the VLA-6 family. Nature (Lond.). 336:487-489.

27. Lotz, M. M., C. A. Korzelius, and A. M. Mercurio. 1990. Human colon carcinoma cells use multiple receptors to adhere to laminin: involvement of $\alpha_{6} \beta_{4}$ and $\alpha_{2} \beta_{1}$. Cell Regul. 1:249-257.

28. de Luca, M., R. N. Tamura, S. Kajiji, S. Bondanza, P. Rossino, R. Cancedda, P. C. Marchisio, and V. Quaranta. 1990. Polarized integrin mediates human keratinocyte adhesion to basal laminin. Proc. Natl. Acad. Sci USA. 87:68886892.

29. Larjava, H., J. Peltonen, S. K. Akiyama, S. S. Yamada, H. R. Gralnick, J. Uitto, and K. M. Yamada. 1990. Novel function for $\beta_{1}$ integrins in keratinocyte cell-cell interactions. J. Cell Biol. 110:803-815.

30. Carter, W. G., P. Kaur, S. G. Gil, P. J. Gahr, and E. A. Wayner. 1990 Distinct functions for integrins $\alpha 3 \beta 1$ in focal adhesions and $\alpha 6 \beta 1$ /bullous pemphigoid antigen in a new stable anchoring contact (SAC) of keratinocytes. Relation to hemidesmosomes. J. Cell Biol. 111:3141-3154.
31. Marchisio, P. C., S. Bondanza, O. Cremona, R. Cancedda, and M. De Luca. 1991. Polarized expression of integrin receptors $\left(\alpha_{6} \beta_{4}, \alpha_{2} \beta_{1}, \alpha_{3} \beta_{1}\right.$, and $\left.\alpha_{v} \beta_{5}\right)$ and their relationship with the cytoskeleton and basement membrane matrix in cultured human keratinocytes. J. Cell Biol. 112:761-773.

32. Lampugnani, M. G., M. Resnati, E. Dejana, and P. C. Marchisio. 1991. The role of integrins in the maintenance of endothelial monolayer integrity. $J$. Cell Biol. 112:479-490.

33. Aplin, J. D., A. K. Charlton, and S. Ayad. 1988. An immunohistochemical study of human endometrial extracellular matrix during the menstrual cycle and first timester of pregnancy. Cell Tissue Res. 253:231-240.

34. Tabibzadeh, S. S. 1990. VLA-1 associated with endometrial biopsies. Fertil. Steril. 54:624-631.

35. Tabibzadeh, S. S., and P. Satyaswaroop. 1990. Progestin-mediated induction of VLA-1 in glandular epithelium of human endometrium, in vitro. The 72nd Annual Meeting of the Endocrine Society. 199:700. (Abstr.)

36. Lawler, J., R. Weinstein, and R. O. Hynes. 1988. Cell attachment to thrombospondin: the role of Arg-Gly-Asp, calcium, and integrin receptors. $J$. Cell Biol. 262:17249-17298.

37. Cheresh, D. A., J. W. Smith, H. M. Cooper, and V. Quaranta. 1989. A novel vitronectin receptor receptor integrin $(\alpha v \beta x)$ is responsible for distinct adhesive properties of carcinoma cells. Cell. 57:59-69.

38. Bodary, S. C., and J. W. McLean. 1990. The integrin $\beta 1$ subunit associates with the vitronectin receptor $\alpha \mathrm{v}$ subunit to form a novel vitronectin receptor in a human embryonic kidney cell line. J. Biol. Chem. 265:5938-5941.

39. Ramaswamy, H., and M. E. Hemler. 1990. Cloning, primary structure, and properties of a novel human integrin beta subunit. EMBO (Eur. Mol. Biol. Organ.) J. 9:1561-1568.

40. Sheppard, D., C. Rozzo, L. Starr, V. Quaranta, D. J. Erle, and R. Pytela. 1990. Complete amino acid sequence of a novel integrin subunit $(\beta 6)$ identified in epithelial cells using the polymerase chain reaction. J. Biol. Chem. 265:1150211507.

41. Busk, M., R. Pytela, V. Quaranta, and D. Sheppard. 1991. The novel integrin $\alpha \mathrm{v} / \beta 6$ is a fibronectin receptor on airway epithelial cells. Am. Rev. Respir. Dis. A402. (Abstr.)

42. Navot, D., P. A. Bergh, M. Williams, F. J. Garrisi, I. Guzman, B. Sandler, J. Fox, P. Schreiner-Engel, G. E. Hofmann, and L. Grunfeld. 1991. An insight into early reproductive processes through the in vivo model of ovum donation. $J$ Clin. Endocrinol. \& Metab. 72:408-414.

43. Haymen, E. G., M. D. Pierschbacher, Y. Öhgren, and E. Ruoslahti. 1983. Serum spreading factor (vitronectin) is present at the cell surface and in tissues. $J$. Cell Biol. 80:4003-4007.

44. Armant, D. R., H. A. Kaplan, H. Mover, and W. J. Lennarz. 1986. The effect of hexapeptides on attachment and outgrowth of mouse blastocysts cultured in vitro: evidence for the involvement of the cell recognition tripeptide Arg-Gly-Asp. Proc. Natl. Acad. Sci. USA. 83:6751-6755.

45. Kao, L.-C., S. Caltabiano, S. Wu, J. F. Strauss, III, and H. J. Kliman. 1988. The human villous cytotrophoblast: interactions with extracellular matrix proteins, endocrine function, and cytoplasmic differentiation in the absence of syncytium formation. Development (Camb.). 130:693-702.

46. Zhu, B. C.-R., S. F. Fisher, H. Pande, J. Calaycay, J. E. Shively, and R. A. Laine. 1984. Human placental (fetal) fibronectin: increased glycosylation and higher protease resistance than plasm fibronectin. J. Biol. Chem. 259:3962-3970.

47. Feinberg, R. F., H. J. Kliman, and C. J. Lockwood. 1991. Is oncofetal fibronectin a trophblast glue for human implantation. Am. J. Pathol. 138:537543.

48. Lessey, B. A., A. P. Killam, D. A. Metzger, A. F. Haney, G. L. Greene, and K. S. McCarty, Jr. 1988. Immunohistochemical analysis of human uterine estrogen and progesterone receptors throughout the menstrual cycle. J. Clin. Endocrinol. Metab. 67:334-340.

49. Garcia, E., P. Bouchard, J. de Brux, J. Berdah, R. Frydman, G. Schaison E. Milgrom, and M. Perrot-Applanat. 1988. Use of immunocytochemistry of progesterone and estrogen receptors for endometrial dating. J. Clin. Endocrinol. Metab. 67:80-87.

50. Ignotz, R. A., J. Heino, and J. Massague. 1989. Regulation of cell adhesion receptors by transforming growth factor- $\beta$. J. Biol. Chem. 264:389-392.

51. Heino, J., R. A. Ignotz, M. E. Hemler, C. Crouse, and J. Massague. 1989 Regulation of cell adhesion receptors by transforming growth factor- $\beta$. J. Biol. Chem. 264:380-388. 